\title{
IX. On the expected reappearance of the celebrated comet of 1264 and 1556
}

\author{
Mr. Hind
}

To cite this article: Mr. Hind (1847) IX. On the expected reappearance of the celebrated comet of 1264 and 1556, Philosophical Magazine Series 3, 31:205, 50-55, DOI:

10.1080/14786444708645781

To link to this article: http://dx.doi.org/10.1080/14786444708645781

册 Published online: 30 Apr 2009.

Submit your article to this journal $₫$

Џ Article views: 2

Q View related articles $₫$ 


\section{On the expected Reappearance of the celebrated Comet of 1264 and 1556. By Mr. Hind*.}

$\checkmark \mathrm{HE}$ time is now near at hand when the return of the comet 1 of 1264 and 1556 , signalised by $\mathrm{Mr}$. Dunthorne and $\mathrm{M}$. Pingré, may be expected to take place. It is therefore desirable that observers should be in possession of everything that may tend to facilitate their search for the comet; and I venture to communicate to the Society the results of some recent calculations of my own on the subject, preceded by a very brief view of the principal circunstances connected with former appearances of the comet, and a short notice of calculations already published.

"The great and celebrated comet" of 1264, as Pingré terms it, is mentioned by nearly all the European historians of the time, and was observed by the astronomers of the dynasties then reigning in the north and south of China. It is described as presenting a most imposing appearance, with a tail $100^{\circ}$ in length, stretching from the east part of the " midheaven." The comet was of "surprising magnitude," far exceeding any remembered by those who beheld it. Contemporary writers generally considered it the precursor of the death of Pope Urban IV., and many of them relate that it disappeared on the same night that the pope died, or on October 2; thus, in the words of Thierri de Vaucouleurs,

"Quo (Urbano) moriente, velut mortem cognosceret ejus, Apparens minimè stella comata fuit."

In 1556 the appearance of the comet was not on the same scale of splendour as in 1264, but still was sufficiently imposing to call forth from historians the epithets "ingens et lucidum sidus." It was observed by Paul Fabricius, a mathematician and physician at the court of the emperor Charles V. of Austria. M. Pingré, the celebrated cometographer, sought in vain for the original observations; the only information he could find on the subject was contained in a small rough chart found in Lycosthenes and other authors. I have before $\dagger$ suggested the probability that these observations were given by Fabricius in his work upon the comet, published at Nürnberg in 1556, and mentioned by Lalande in his Bibliographie; but, as far as I am aware, this work has not been discovered in any library. M. Pingré would have at his command the splendid collections of St. Geneviève and the Royal Library at Paris; and his ineffectual search for the observations in these libraries makes it at least doubtful whether they are now in existence. The chart just mentioned enables us to form a tolerably definite

* From the Proceedings of the Royal Astronomical Society, No. 14.

† Ast. Nach. 493. 
idea of the path followed by the comet, and we have ample information for a rough determination of the elements.

When Halley published his Synopsis of Cometary Astronomy, he gave a set of parabolic elements for the comet of 1556, founded upon the observations made by Paul Fabricius; but he remarks that these elements are not so certain as those of other comets he had computed, the observations being made " neither with sufficient instruments nor due care," and by no means to be reconciled with any regular calculation.

The elements of the comet of 1264 were first computed by Mr. Dunthorne. His discussion of the observations and circumstances relating to the comet's apparition are published in vol. xlvii. of the Philosophical Transactions. The elements are chiefly founded on the authority of a manuscript preserved in the library of Pembroke Hall College, Cambridge, entitled Tractatus fratris Agidii de Cometis. But it must be observed there are manifest contradictions in this account not easily set right. The other authorities consulted were the Chronicon Sampetrinum Erphurtense and the Chronicle of John Vitoduranus. The orbit deduced by $\mathrm{Mr}$. Dunthorne much resembles that calculated by Halley for the comet of 1556 .

In the Memoirs of the Royal Academy of Sciences at Paris for 1760 , appears a valuable memoir by M. Pingré on the comet of 1264. After collecting together a great number of accounts from different chronicles and histories of the day, he proceeds to the discussion of the elements. The contradiction in the Cambridge manuscript which relates to the comet's motion in longitude is pointed out; and since this manuscript was $\mathrm{Mr}$. Dunthorne's chief authority, it might be supposed that his orbit would differ entirely from M. Pingré's. This, however, was not the case; for although there are differences of some moment in one or two of the elements, there is still a striking similarity between the two orbits taken as a whole, and M. Pingré's approaches much nearer than Mr. Dunthorne's to the orbit of the comet of 1556. A closer agreement might have been produced if he had not wished to preserve the path laid down by Thierri de Vaucouleurs with as little alteration as possible. M. Pingré concludes from his researches that there is little doubt of the identity of the comets of 1264 and 1556 , and, therefore, that the return to perihelion may be expected to take place in the year 1848. In No. 493 of the Astronomische Nachrichten will be found the results of my first calculations relating to this comet. I have there deduced elements from the observations by Fabricius in 1556, and computed an ephemeris for comparison with the comet's observed path. The agreement, though not so close as could be wished, was the best that could be obtained from the data E 2 
given by M. Pingré in his Cometography. I then reduced the elements to the year 1264, and with the assistance of a passage in Thierri's poem, I fixed the time of perihelion for July 9.9 (old style). The passage alluded to is as follows :-

"Undecimumque gradum Phœbo superante Leonis, Ter deno Cancri restitit illa loco."

With M. Pingré, I have understood by "Ter deno Cancri," the 120 th degree of longitude; but I am not quite sure that this is the true interpretation.

With peribelion and node reduced as before stated, and the other elements as for 1556 , an ephemeris of the comet's geocentric path in 1264 was computed. During the month of July, calculation and observation agree pretty well; but after the begimning of August the theoretical places entirely differ from the positions of the comet, as deduced from the accounts. Instead of traversing Orion towards the end of its appearance, as some historians relate, it would take a higher declination, passing through Auriga and Taurus.

Since the publication of this paper in the Astronomische Nachrichten, I have made some further investigations on the subject, and with more success than in my first calculations. A closer comparison of data showed pretty clearly that the observation of March 5, on which I had chiefly relied, must be erroneous as it is given by M. Pingré. In tome $i$, of his Cometography, p. 503, we learn that on March 5 the comet was almost in the right line joining the stars $\gamma$ and $\theta$ Virginis, and was equidistant from the stars. A trigonometrical calculation from these data gives the place of the comet in longitude $188^{\circ} 1^{\prime}$, and latitude $+2^{\circ} 19^{\prime}$, and this position was employed in my earlier investigations. But I have recently satisfied myself, that the observation as given above cannot be reconciled with those of March 3 and 4, and on subsequent days, by any set of elements. The cause of this anomaly is, $I$ believe, an error in the name of the star. If instead of $\gamma$ and $\theta$ Virginis we read $\delta$ and $\theta$, then the place of the comet would be in longitude $188^{\circ} 41^{\prime}$, and Jatitude $+5^{\circ} 13^{\prime}$, which agrees very well with the track which the comet ought to have followed, according to the other observations.

A recalculation of the elements from an interpolated position for March 5, and from those of March 9 and 14, gives the following values:-

Passage through perihelion, 1556, April 22.0233, G. M. T. [Old style.]

Longitude of perihelion

Ascending $27^{\circ} \quad 1^{\prime} \cdot 9$

Inclination $175 \begin{aligned} & 25 \cdot 8 \\ & 25 q u i n o x\end{aligned}$ of 1556.

Log. least distance $3012 \cdot 2$

$9 \cdot 70323$

Motion direct. 
The following ephemeris of the comet for the appearance in 1556, Greenwich mean midnight, old style, is deduced from these elements:-

\begin{tabular}{|c|c|c|c|c|}
\hline $\begin{array}{c}1836 . \\
\text { old style. }\end{array}$ & Geo. long. & Geoc. lat. & $\log \cdot r$ & $\Delta$. \\
\hline March & $188 ̊ 13$ & $\begin{array}{r}\circ \\
+\quad \mathbf{9}\end{array}$ & 0.0732 & $0 \cdot 193$ \\
\hline & $188 \quad 0$ & 340 & 0.0670 & $0 \cdot 175$ \\
\hline & 18744 & 645 & $0 \cdot 0606$ & $0 \cdot 157$ \\
\hline & 18722 & 1036 & $0 \cdot 0541$ & $0 \cdot 140$ \\
\hline$g$ & 18654 & $15 \quad 29$ & $0 \cdot 0476$ & $0 \cdot 124$ \\
\hline & $186 \quad 14$ & 2143 & $0 \cdot 0409$ & 0. 109 \\
\hline & $185 \quad 18$ & 2949 & 0.0341 & 0.096 \\
\hline 10 & 18349 & 4012 & 0.0272 & $0 \cdot 085$ \\
\hline 1 & $181 \quad 11$ & 5250 & 0.0201 & 0.078 \\
\hline 1 & 17521 & 675 & 0.0130 & 0.075 \\
\hline 1 & 15335 & 8029 & 0.0057 & 0.078 \\
\hline 1 & $\begin{array}{ll}55 & 19\end{array}$ & 8230 & $9 \cdot 9983$ & 0.085 \\
\hline 1. & 2716 & 7326 & 99908 & 0.095 \\
\hline 1 & 2037 & 6530 & 9.9831 & $0 \cdot] 08$ \\
\hline 1 & 1744 & $\begin{array}{ll}59 & \mathrm{~J} 6\end{array}$ & 9.9753 & 0.122 \\
\hline 2 & 1219 & $34 \quad 58$ & $9 \cdot 8903$ & 0.302 \\
\hline April & 127 & 271 & $9 \cdot 7959$ & 0.505 \\
\hline 1 & 1413 & 2030 & $9 \cdot 7178$ & 0.733 \\
\hline 2 & 1912 & +1352 & $9 \cdot 7130$ & 0.974 \\
\hline
\end{tabular}

If this ephemeris be compared with the descriptions of the comel's apparent path in the heavens, we shall find the agreement as close as could be expected, considering the uncertainty and irregularity of the data.

With the above elements reduced to 1264 , the time of perihelion was found to be July $13 \cdot 42$, i. e. assuming with Pingré, that the comet was in longitude $120^{\circ}$ when the sun had reached the 11 th degree of Leo, according to the narration of Thierri de Vaucouleurs. The geocentric places of the comet, Greenwich mean midnight, old style, would then be as follows :-

\begin{tabular}{|c|c|c|c|c|}
\hline $\begin{array}{l}1264 . \\
\text { old style. }\end{array}$ & Geo. long. & Geoc. lat. & $r$ & $\Delta$. \\
\hline July 7 & $138^{\circ} 10^{\prime}$ & $+18^{\circ} 14$ & 0.53 & 0.82 \\
\hline 17 & 13236 & $22 \quad 9$ & $0.5 \mathrm{I}$ & 0.62 \\
\hline 22 & 12629 & 2154 & 0.55 & 0.55 \\
\hline 27 & 11836 & 2014 & 0.61 & 0.48 \\
\hline Aug. 6 & 10114 & +1017 & 0.75 & 0.41 \\
\hline 16 & $85 \quad 23$ & -347 & 0.92 & 0.39 \\
\hline 26 & $\begin{array}{lll}70 & 47\end{array}$ & 1710 & $1 \cdot 09$ & 0.42 \\
\hline Sept. 5 & 5639 & 278 & $1 \cdot 26$ & 0.48 \\
\hline 15 & 4311 & 334 & $1 \cdot 43$ & 0.57 \\
\hline 25 & 3135 & 3526 & 1.59 & $0 \cdot 69$ \\
\hline Oct. $\mathbf{5}$ & 2247 & -3530 & 1.75 & 0.84 \\
\hline
\end{tabular}

If we are to depend solely on the European accounts of this comet's path, the above is liable to two objections : first, too high a declination in August; and secondly, that the posi- 
tions are in Eridanus during the latter part of the comet's apparition; historians generally contenting themselves with stating that the comet "finally traversed Orion." M. Pingré's elements, which are not open to these objections, do not agree so well as mine with the more circumstantial details left us in the Chinese annals. The two orbits differ chiefly in the longitude of the node and perihelion distance, but the discordances are by no means great.

The results of my calculations have satisfied me that the comet of 1264 was, in all probability, the same as that of 1556 , and consequently, that its return to perihelion must be very near at hand. 'The nodes of the comet's orbit lie very close to the earth's path. The ascending node is passed fifty days before perihelion, the radius vector being $1 \cdot 193$, and consequently the distance outside the earth's orbit about 0.197 . The passage through descending node occurs $31 \frac{1}{2}$ days after perihelion, and the distance of the point from the earth's orbit inside is $0 \cdot 126$. However, the nearest approach of the comet to the earth will not happen at the nodes, but soon after its passage through them; thus in 1556 the least distance between the two bodies was 0.074 , nine days after the transit through ascending node. The effect of this close proximity to our globe on the period of revolution of the comet has been investigated by Professor Mädler, of the Dorpat Observatory, as detailed in No. 501 of the Astronomische Nachrichten; it amounted to $14 \cdot \frac{1}{2}$ days only, and the return of the comet to perihelion was fixed for the end of February 1848.

The following table contains the heliocentric co-ordinates referred to the equator and the log. radii vectores of the comet in my last orbit, reduced to 1848 , for every tenth day, from ninety days before to $\mathbf{9 0}$ days after perihelion.

\begin{tabular}{|c|c|c|c|c|}
\hline $\begin{array}{l}\text { Time from } \\
\text { perihelion pass. }\end{array}$ & $a$. & $y$. & $\approx$ & Log. $r$ \\
\hline $\begin{array}{c}\text { Days. } \\
-90\end{array}$ & $-1 \cdot 7430$ & +0.5750 & -0.0603 & $0 \cdot 2640$ \\
\hline 80 & $1 \cdot 6231$ & 0.4370 & 0.0445 & 0.2257 \\
\hline 70 & $1 \cdot 4931$ & 0.2963 & 0.0284 & $0 \cdot 1826$ \\
\hline 60 & $1 \cdot 3504$ & $0 \cdot 1533$ & -0.0122 & $0 \cdot 1333$ \\
\hline 50 & $1 \cdot 1917$ & +0.0084 & +0.0041 & 0.0762 \\
\hline 40 & 1.0120 & -0.1363 & 0.0206 & 0.0092 \\
\hline 30 & $0 \cdot 8039$ & 0.2770 & 0.0363 & $9 \cdot 9300$ \\
\hline 20 & $0 \cdot 5570$ & 0.4031 & $0 \cdot(\$ 501$ & $\mathbf{9} \cdot 8385$ \\
\hline-10 & -0.2611 & 0.4907 & $0 \cdot 059 \mathrm{~d}$ & $9 \cdot 7474$ \\
\hline 0 & +0.0738 & 0.4961 & $0 \cdot 0583$ & $9 \cdot 7032$ \\
\hline+10 & 0.3929 & $0 \cdot 3951$ & 0.0450 & $9 \cdot 7474$ \\
\hline 20 & 0.6507 & 0.2266 & $0 \cdot 0239$ & $9 \cdot 8385$ \\
\hline 30 & $0 \cdot 8503$ & -0.0352 & +0.0004 & $9 \cdot 9300$ \\
\hline 40 & $1 \cdot 0086$ & +0.1590 & -0.0233 & 0.0092 \\
\hline 50 & $1 \cdot 1385$ & 0.3490 & $0 \cdot 0463$ & 0.0762 \\
\hline 60 & $1 \cdot 2484$ & 0.5331 & $0.068 \overline{5}$ & $0 \cdot 1333$ \\
\hline 70 & $1 \cdot 3433$ & 0.7109 & $0 \cdot 0900$ & 0.1826 \\
\hline 80 & $1 \cdot 4268$ & 0.8828 & $0 \cdot 1107$ & 0.2257 \\
\hline+90 & +1.5015 & +1.0492 & -0.1307 & $0 \cdot 2640$ \\
\hline
\end{tabular}


With the above values for $x, y$ and $z$, and those of $\mathrm{X}, \mathrm{Y}$, $Z$, taken from the Nautical Almanac, the position of the comet for different suppositions as to the time of passage through perihelion may be readily obtained. If we suppose March 0 , which is about the epoch fixed by Professor Mädler, we shall have the following ephemeris for facilitating the discovery of the comet, mean noon at Greenwich :-

\begin{tabular}{|c|c|c|c|}
\hline $1847-8$. & R.A. & Decl. & $\Delta$. \\
\hline Dec. 1 & $187^{\circ} 16^{\prime}$ & $-11 \mathfrak{2} 2$ & $2 \cdot 16$ \\
\hline 11 & 19355 & 1256 & 1.92 \\
\hline 21 & 20152 & 1429 & $1 \cdot 68$ \\
\hline 31 & 21143 & 1552 & $1 \cdot 46$ \\
\hline Jan. 10 & 22416 & 1650 & 1.26 \\
\hline 20 & 24018 & 1647 & $1 \cdot 11$ \\
\hline 30 & 25953 & 153 & $1 \cdot 02$ \\
\hline Feb. 9 & 28123 & 1124 & $1 \cdot 03$ \\
\hline 19 & 302 I5 & 71 & $1 \cdot 13$ \\
\hline 29 & 32118 & 323 & 1.29 \\
\hline Mar. 10 & $338 \quad 5$ & -054 & $\mathrm{l} \cdot 48$ \\
\hline 20 & 35211 & +050 & $1 \cdot 66$ \\
\hline 30 & 350 & 29 & 1.84 \\
\hline April 9 & 1332 & 311 & $2 \cdot 01$ \\
\hline 19 & 2146 & 359 & $2 \cdot 17$ \\
\hline 29 & 2852 & 435 & $2 \cdot 32$ \\
\hline May 9 & $35 \quad 5$ & 458 & 2.46 \\
\hline 19 & 4036 & 511 & $2 \cdot 59$ \\
\hline 29 & 4531 & +512 & $2 \cdot 69$ \\
\hline
\end{tabular}

It appears from this ephemeris, that according to the most probable supposition we can make respecting the time of perihelion without actual calculation of the perturbations, the position of the comet in the heavens during the approaching reappearance will be extremely unfavourable for observation; and it is therefore the more desirable that those who look out for comets should be on the alert. Nearly the whole of the vast trajectory of this comet lies below the plane of the ecliptic, and far from the paths of the larger planets, but it extends into space more than twice the distance of Neptune; and surely we are not yet able to say what causes may operate, at this immense distance from the sun, to affect the time of the next return to perihelion. If however the comet can be detected and observed, we shall then have the means of ascertaining something more on these points 